\title{
Carbothermic Reduction of Oxide Powder Prepared from Titanium Dioxide and Cobalt Nitrate
}

\author{
Gil-Geun Lee ${ }^{1}$ and Gook-Hyun $\mathrm{Ha}^{2}$ \\ ${ }^{1}$ Division of Materials Science \& Engineering, Pukyong National University, Yongdang-dong, Nam-gu, Busan 608-739, Korea \\ ${ }^{2}$ Korea Institute of Machinery \& Materials, Sangnam-dong, Changwon, Kyungnam 641-010, Korea
}

\begin{abstract}
The carbothermic reduction of a titanium-cobalt-oxygen-based oxide powder was analyzed to understand the carbothermal reduction step of the spray thermal conversion process for the synthesis of titanium carbide/cobalt composite powder. The starting powder was prepared by the combination of the spray drying and desalting methods using titanium dioxide powder and cobalt nitrate. The synthesized oxide powders were mixed with carbon black, and then these mixtures were heat treated under a flowing argon atmosphere. The changes in the phase structure and thermal gravity of the mixtures during heat treatment were analyzed using XRD and TG-DTA. The synthesized oxide powders have a mixed phase structure of anatase- $\mathrm{TiO}_{2}$ and $\mathrm{CoTiO}_{3}$ phases without regard to the cobalt content. These composite oxide powders were carbothermally reduced to the titanium carbide/cobalt composite powder through four steps with increasing temperature; reduction of $\mathrm{CoTiO}_{3}$, reduction of anatase- $\mathrm{TiO}_{2}$, formation of titanium oxycarbide and formation of $\mathrm{TiC}$ from titanium oxycarbide. The titanium carbide formability increased with the increasing relative amount of the complex oxide, $\mathrm{CoTiO}_{3}$, in the titanium-cobalt-oxygen-based oxide powder. [doi:10.2320/matertrans.47.3007]
\end{abstract}

(Received July 24, 2006; Accepted October 30, 2006; Published December 15, 2006)

Keywords: titanium carbide, titanium dioxide, carbothermal reduction, powder, hard metals

\section{Introduction}

The tool materials manufactured by the powder metallurgy process consist of a composite microstructure of hard particles dispersed in a soft binder matrix. Generally, WC, $\mathrm{TiC}, \mathrm{TaC}, \mathrm{NbC}$ and $\mathrm{Ti}(\mathrm{C}, \mathrm{N})$ particles have been used as the dispersion material, and $\mathrm{Co}$ and $\mathrm{Ni}$ as the matrix. ${ }^{1)}$ The mechanical properties of the tool materials depend not only on the chemical composition, but also on their microstructure. ${ }^{2)}$ The hardness, fracture toughness and wear properties of the tool materials are significantly influenced by the size of the hard particles and the distance of the mean free path among the hard particles. These mechanical properties simultaneously increased with the decreasing particle size and the distance of the mean free path. To manufacture a high performance tool material with an ultrafine microstructure, raw powder materials with an ultrafine particle size should be used. Several methods have been proposed for the synthesis of ultrafine particles. ${ }^{3-6)}$ In the case of $\mathrm{WC}$, it was possible to synthesize the WC/Co composite powder with an average particle size of under $100 \mathrm{~nm}$ by a mechano-chemical process. ${ }^{6}$ For the other carbides, however, no commercial process has been established for the synthesis of such ultrafine particles.

Titanium carbide (TiC) has been used as a dispersion particle in the WC-TiC-Co tool materials to increase the high temperature hardness and to prevent a reaction with the steel alloy during machining, and is also extensively used in the cermet tool materials of $\mathrm{TiC}$ and $\operatorname{Ti}(\mathrm{C}, \mathrm{N})$ systems. $^{7-9)} \mathrm{A}$ number of processes exist for synthesizing titanium carbide, such as the carbothermal reduction of titanium dioxide, ${ }^{10)}$ direct carbarization of titanium, ${ }^{11)}$ chemical reaction of titanium chloride $\left(\mathrm{TiCl}_{4}\right),{ }^{12)}$ self-propagating high temperature synthesis, ${ }^{13)}$ etc. Generally, these processes require a temperature range of $1700-2100 \mathrm{~K}$ for the commercial production of the titanium carbide powder. Therefore, it is difficult to produce fine particles using these processes due to the agglomeration of each particle at the high synthesis temperature. Recently, a new spray thermal conversion process was proposed for the synthesis of ultrafine titanium carbide powders. ${ }^{14)}$ This process is composed of three steps; the synthesis of the precursor powder by spray drying of an aqueous slurry of the mixture of titanium dioxide powder and a cobalt salt, desalting treatment of the precursor powder, and carbothermic reduction of the desalted powder. This process has the characteristic of using cobalt as an agglomeration inhibitor of the titanium carbide particles. The final product has a more homogeneous mixing state of the titanium carbide and cobalt than that in the conventionally mixed powder, therefore, this can be used as the raw powder for high performance tool materials. The characteristics of the TiC/ Co composite powder synthesized by the spray thermal conversion process will depend on process parameters; i.e., spray drying condition, desalting temperature, carbothermic reduction temperature/time, cobalt content, etc. The process parameters of the carbothermic reduction were very important for the control of the properties of the carbide particles synthesized by the carbothermal reduction process. To obtain a homogeneous ultrafine $\mathrm{TiC} / \mathrm{Co}$ composite powder, the spray thermal conversion process should be precisely controlled based on understanding the carbothermic reduction step. The chemical mechanism of the carbothermic reduction of the titanium dioxide powder is well known. ${ }^{15-17)}$ However, the chemical reaction of the titanium-cobalt-oxygen-based oxide powder synthesized by the spray drying has been rarely studied.

In the present study, the focus is the basic analysis of the carbothermic reduction of the titanium-cobalt-oxygen-based oxide powder in order to understand the carbothermal reduction step in the spray thermal conversion process.

\section{Experimental Procedure}

The starting slurry was prepared by suspending the 
titanium dioxide powder (an average particle size of $50 \mathrm{~nm}$ and anatase structure) in an aqueous solution of cobalt nitrate, $\mathrm{Co}\left(\mathrm{NO}_{3}\right)_{3} 6 \mathrm{H}_{2} \mathrm{O}$, to obtain a final composition of $\mathrm{TiC} \sim \mathrm{TiC}$ 15 mass $\%$ Co. Spray drying was performed using a rotary atomizer with a slurry feed rate of $3.3 \times 10^{-7} \mathrm{~m}^{3} \mathrm{~s}^{-1}$ and an atomizer rotating speed of $183 \mathrm{~s}^{-1}$ in a hot air $(523 \mathrm{~K})$ stream. A precursor powders obtained by the spray drying were decomposed at $1073 \mathrm{~K}$ for $7.2 \mathrm{ks}$ in air to remove the salt components and form a titanium-cobalt-oxygen-based oxide powder. The calcined oxide powders were mixed with carbon black (mean particle size: $0.5 \mu \mathrm{m}$ ) for $86.4 \mathrm{ks}$ using a tumbler-ball mill with a ball/powder mass ratio of 10:1. The mixtures were placed in a graphite crucible and $1 \times$ $10^{-2} \mathrm{~kg}$ of the mixture was heated in the temperature range from 1073 to $1673 \mathrm{~K}$ for $1.8 \mathrm{ks}$ in a tube furnace with flowing argon (purity: 99.7\%). After the heat treatment, the samples were analyzed by $\mathrm{X}$-ray diffraction using $\mathrm{Cu}-\mathrm{K}_{\alpha}$ radiation and observed by SEM. The changes in the thermal gravity of these powder mixtures from room temperature to $1673 \mathrm{~K}$ in flowing argon were recorded by TG-DTA at the heating rate of $8.3 \times 10^{-2} \mathrm{Ks}^{-1}$.

\section{Results and Discussion}

Figure 1 shows the X-ray diffraction patterns of the synthesized titanium-cobalt-oxygen-based oxide powders for the final composition of $\mathrm{TiC} \sim \mathrm{TiC}-15$ mass $\%$ Co made by the spray drying and desalting processes. The calcined powders for the final composition of $\mathrm{TiC}-5$ mass $\% \mathrm{Co}$ and TiC-15 mass $\%$ Co showed diffraction peaks of anatase- $\mathrm{TiO}_{2}$

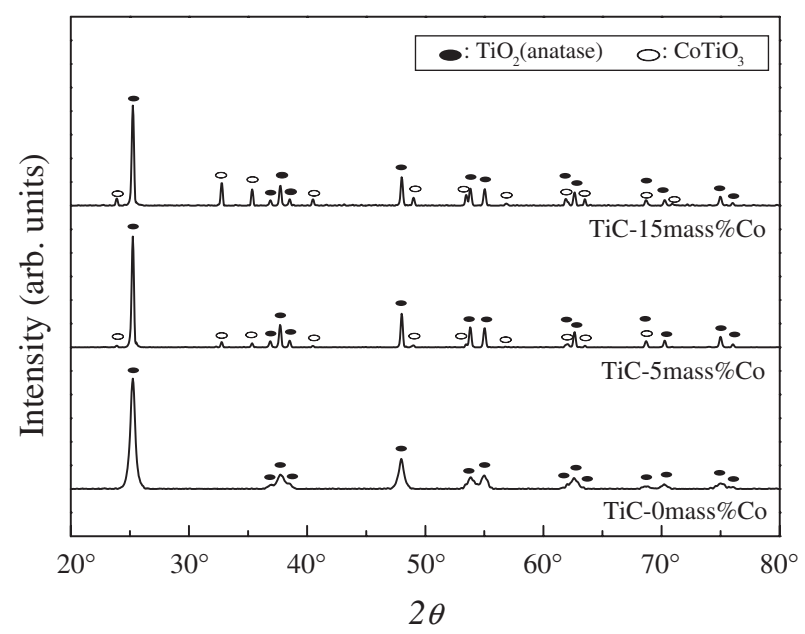

Fig. 1 X-ray diffraction patterns of synthesized starting oxide powders by combination of spray drying and desalting processes. and $\mathrm{CoTiO}_{3}$ phases. The anatase- $\mathrm{TiO}_{2}$ phase was less stable than the rutile-phase-structured one. ${ }^{18)}$ In general, titanium dioxide of the metastable anatase phase transforms into the stable rutile phase during heating. In this study, the phase transformation of the titanium dioxide was not found during desalting at $1073 \mathrm{~K}$ for $7.2 \mathrm{ks}$. However, a chemical reaction occurred between the titanium dioxide and cobalt component during desalting. The entire cobalt component in the precursor powder was transformed into the complex oxide state, $\mathrm{CoTiO}_{3}$. Clearly, a part of the titanium dioxide in the precursor powder was transformed into this complex oxide. The relative intensity of the X-ray peak of this $\mathrm{CoTiO}_{3}$ to that of anatase- $\mathrm{TiO}_{2}$ increased with the increasing cobalt content.

Figure 2 shows SEM micrographs of the synthesized starting oxide powder for the final compositions of TiC, TiC5 mass \% Co and TiC-15 mass\%Co. The synthesized starting oxide powders from the spray drying process have a spherical morphology with an average particle size of about $50 \mu \mathrm{m}$. These spherical particles are composed of loosely agglomerated fine particles with a sub-micrometer size. Figure 2 shows micrographs of the primary particles on the surface of a secondary spherical particles. For the final composition of $\mathrm{TiC}$, the average particle size was about $50 \mathrm{~nm}$, which was the same size as the raw $\mathrm{TiO}_{2}$, and these primary particles were loosely agglomerated. The size of the agglomerates was larger, about $100 \mathrm{~nm}$, in the samples with the final composition of TiC-5 mass \% Co and TiC-15 mass\%Co. The primary particle size of the mixture of $\mathrm{CoTiO}_{3}$ and $\mathrm{TiO}_{2}$ was larger than that of the $\mathrm{TiO}_{2}$, due to the chemical reaction between the titanium dioxide and cobalt during desalting. There was no notable difference in the primary particle size with the amount of cobalt.

Figure 3 shows the mass change of the mixture of the calcined oxide powder and carbon black as a function of the temperature during heating in the flowing argon gas. The theoretical quantities of the carbon for the carbothermal reduction of the calcined powder are estimated by:

$$
\mathrm{TiO}_{2}+\mathrm{CoTiO}_{3}+7 \mathrm{C} \rightarrow 2 \mathrm{TiC}+\mathrm{Co}+5 \mathrm{CO}
$$

In this study, $10 \%$ excess carbon was used for the reaction. In the sample of the $\mathrm{TiC}$ composition, the titanium dioxide powder started to decrease its mass around $1273 \mathrm{~K}$, and showed a remarkable decrease in the mass fraction at about $1473 \mathrm{~K}$. In the sample of the final TiC-5 mass\%Co and TiC15 mass \%Co compositions, a mass loss occurred at about $1073 \mathrm{~K}$, and a significant mass loss at about $1373 \mathrm{~K}$. These mass losses mean that the carbothermal reactions occur at these temperatures.
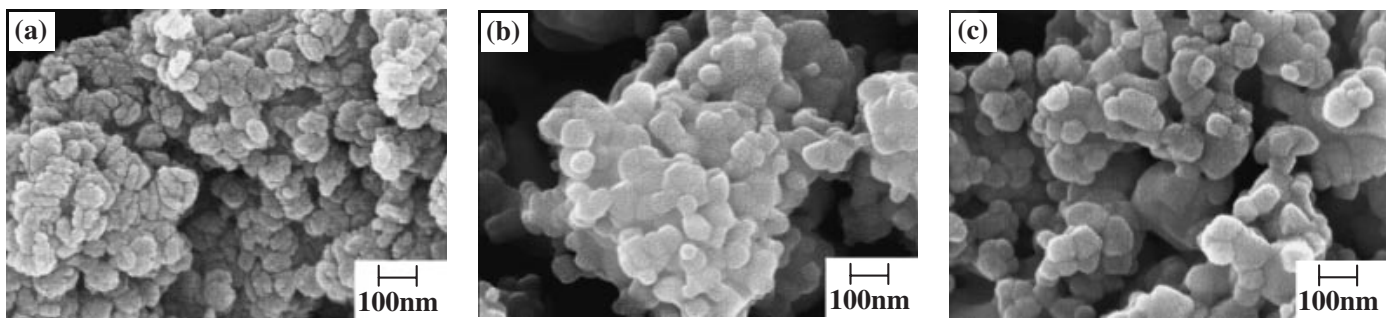

Fig. 2 SEM micrographs of the starting oxide powder for the final composition of (a) TiC, (b) TiC-5 mass \%Co, and (c) TiC- 15 mass $\%$ Co. 


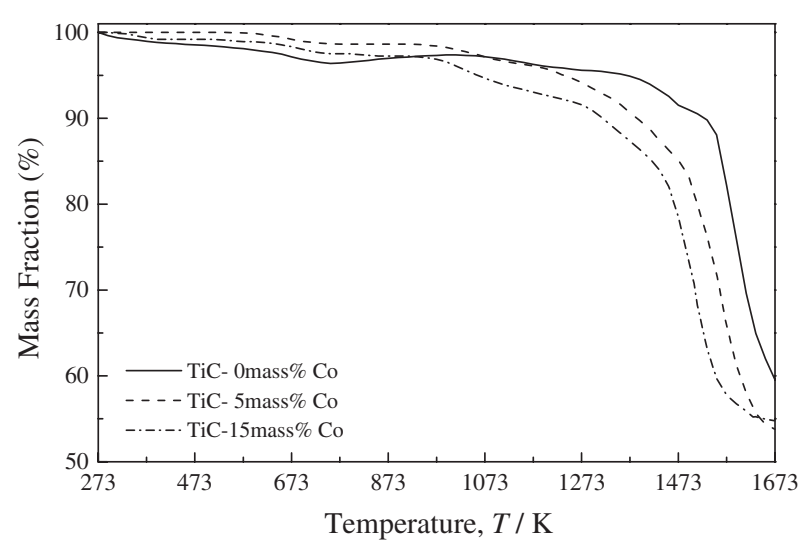

Fig. 3 Change in the mass fraction of the mixtures of the calcined oxide powder and carbon black versus temperature.

Table 1 shows a summary of the phase identification by $\mathrm{X}$-ray diffraction measurements during the carbothermal reduction of the mixtures of the calcined oxide powder and solid carbon. The heat-treatment temperature was determined from the TG curves (Fig. 3). The mixtures were heat treated for $1.8 \mathrm{ks}$. In the case of the final $\mathrm{TiC}$ composition, below $1073 \mathrm{~K}$, the X-ray diffraction patterns showed only an anatase phase $\mathrm{TiO}_{2}$. The diffraction pattern changed to the mixed state of the anatase and rutile-phase $\mathrm{TiO}_{2}$ at $1123 \mathrm{~K}$. At $1273 \mathrm{~K}$, there were two kinds of phases in the heattreated powder; i.e., the magneli phase and a small amount of $\mathrm{TiO}_{2}$. The magneli phase is the lower oxide in the Ti-O system, which is written as $\mathrm{Ti}_{\mathrm{n}} \mathrm{O}_{2 \mathrm{n}-1}(\mathrm{n}>3) .{ }^{9)}$ The X-ray diffraction pattern of the heat-treated powder at $1453 \mathrm{~K}$ showed the coexistance of the $\mathrm{Ti}_{3} \mathrm{O}_{5}$ and magneli phases. At $1473 \mathrm{~K}$, there were three kinds of phases: $\mathrm{Ti}_{3} \mathrm{O}_{5}, \mathrm{Ti}_{2} \mathrm{O}_{3}$ and a small amount of $\mathrm{TiC}_{\mathrm{x}} \mathrm{O}_{\mathrm{y}}$ (as will be shown later using the lattice parameter data in Fig. 5, the initial formation is not pure titanium carbide. It is in fact a solid solution of $\mathrm{TiC}$ and $\mathrm{TiO}$ with the actual formula of $\left.\mathrm{TiC}_{\mathrm{x}} \mathrm{O}_{\mathrm{y}}\right){ }^{19,20)}$ Thermodynamic calculation predicts that the initial composition of $\mathrm{TiC}_{\mathrm{x}} \mathrm{O}_{\mathrm{y}}$ is dependent on the temperature and partial pressure of $\mathrm{CO}$ and will be between $\mathrm{TiC}_{0.6} \mathrm{O}_{0.4}$ and $\mathrm{TiC}_{0.7} \mathrm{O}_{0.3}{ }^{20)}$ The titanium dioxide powder was reduced above $1273 \mathrm{~K}$ by the solid carbon in the flowing argon, and formed $\mathrm{TiC}_{\mathrm{x}} \mathrm{O}_{\mathrm{y}}$ at about $1473 \mathrm{~K}$. The diffraction peak of the added carbon was not detected in the XRD diffraction patterns, because the carbon black had an amorphous-like diffraction pattern around 25 and $45^{\circ}$.

The general reaction of the carbothermal reduction process for the titanium dioxide could be described according to eq. (2).

$$
\mathrm{TiO}_{2}+3 \mathrm{C} \rightarrow \mathrm{TiC}+2 \mathrm{CO}
$$

According to Berger et al. ${ }^{21)}$ the titanium dioxide was carbothermally reduced to $\mathrm{TiC}$ through three steps. In the first reaction step, $\mathrm{CO}$ only acted as a reducing agent and the $\mathrm{Ti}_{\mathrm{n}} \mathrm{O}_{2 \mathrm{n}-1}$ phases were formed as intermediates. In reaction step two, titanium oxycarbide, $\mathrm{TiC}_{\mathrm{x}} \mathrm{O}_{\mathrm{y}}$, was formed by a further reduction accompanied by the incorporation of carbon. In reaction step three, TiC was formed from the titanium oxycarbide. In this study, the titanium dioxide was transformed into the magneli phases and $\mathrm{TiC}_{\mathrm{x}} \mathrm{O}_{\mathrm{y}}$ as the reaction step one and two, respectively, corresponding to the report Berger et al., but the formation of $\mathrm{TiC}$ was not observed for $1.8 \mathrm{ks}$ at $1473 \mathrm{~K}$.

For the final composition of TiC-5 mass\%Co, the X-ray diffraction pattern exhibited anatase- $\mathrm{TiO}_{2}$ and $\mathrm{CoTiO}_{3}$ peaks in the mixed state. These diffraction patterns changed to anatase- $\mathrm{TiO}_{2}$, rutile- $\mathrm{TiO}_{2}$ and $\mathrm{Co}$ peaks at $1073 \mathrm{~K}$. This means that $\mathrm{CoTiO}_{3}$ in the calcined powder was preferentially reduced to the titanium oxide and cobalt below $1073 \mathrm{~K}$. At $1173 \mathrm{~K}$, there were four kinds of phases in the diffraction pattern: rutile- $\mathrm{TiO}_{2}$, anatase- $\mathrm{TiO}_{2}$, cobalt and magneli phases. The X-ray diffraction pattern of the heat-treated powder at $1373 \mathrm{~K}$ showed $\mathrm{Ti}_{3} \mathrm{O}_{5}$, the magneli phase and cobalt. The diffraction patterns of the mixture heat treated at 1453 and $1473 \mathrm{~K}$ showed the peaks of the $\mathrm{Ti}_{3} \mathrm{O}_{5}, \mathrm{Ti}_{2} \mathrm{O}_{3}$, Co and $\mathrm{TiC}_{\mathrm{x}} \mathrm{O}_{\mathrm{y}}$.

For the TiC-15 mass \%Co composition, at $1073 \mathrm{~K}$, there were three kinds of phases in the sample: anatase- $\mathrm{TiO}_{2}$, rutile- $\mathrm{TiO}_{2}$ and cobalt similar for the TiC-5 mass\%Co composition. The $\mathrm{TiC}_{\mathrm{x}} \mathrm{O}_{\mathrm{y}}$ peak could be observed in the $\mathrm{X}$ ray diffraction pattern above $1373 \mathrm{~K}$.

In summary, the titanium dioxide reduced at about $1273 \mathrm{~K}$ and titanium oxycarbide formed at about $1473 \mathrm{~K}$ for the final composition of TiC. For the TiC-5 mass\%Co composition, the reduction temperature of titanium dioxide and the titanium oxycarbide forming temperature decreased to about 1173 and $1453 \mathrm{~K}$, respectively. The titanium dioxide was reduced at about $1173 \mathrm{~K}$ and the titanium oxycarbide formed at about $1373 \mathrm{~K}$, for the final TiC-15 mass\%Co composition.

Table 1 Summary of the change in the XRD peaks during carbothermal reduction of the titanium-cobalt-oxygen-based oxide powders by solid carbon.

\begin{tabular}{|c|c|c|c|}
\hline \multirow{2}{*}{$\begin{array}{c}\text { Temperature } \\
\text { (K) }\end{array}$} & \multicolumn{3}{|c|}{ Identified phases } \\
\hline & TiC-0 mass $\%$ Co & $\mathrm{TiC}-5$ mass $\% \mathrm{Co}$ & $\mathrm{TiC}-15$ mass $\% \mathrm{Co}$ \\
\hline 298 & $\mathrm{a}-\mathrm{TiO}_{2}$ & $\mathrm{a}-\mathrm{TiO}_{2}, \mathrm{CoTiO}_{3}$ & a- $\mathrm{TiO}_{2}, \mathrm{CoTiO}_{3}$ \\
\hline 1073 & $\mathrm{a}-\mathrm{TiO}_{2}$ & $\mathrm{a}-\mathrm{TiO}_{2}, \mathrm{r}-\mathrm{TiO}_{2}, \mathrm{Co}$ & $\mathrm{a}-\mathrm{TiO}_{2}, \mathrm{r}-\mathrm{TiO}_{2}, \mathrm{Co}$ \\
\hline 1123 & $\mathrm{a}-\mathrm{TiO}_{2}, \mathrm{r}-\mathrm{TiO}_{2}$ & - & - \\
\hline 1173 & - & a- $\mathrm{TiO}_{2}, \mathrm{r}-\mathrm{TiO}_{2}$, Magneli, Co & Magneli, $\mathrm{Ti}_{3} \mathrm{O}_{5}, \mathrm{Co}$ \\
\hline 1273 & a- $\mathrm{TiO}_{2}$, Magneli & - & - \\
\hline 1373 & - & Magneli, $\mathrm{Ti}_{3} \mathrm{O}_{5}$, Co & $\mathrm{Ti}_{3} \mathrm{O}_{5}, \mathrm{Ti}_{2} \mathrm{O}_{3}, \mathrm{TiC}_{\mathrm{x}} \mathrm{O}_{\mathrm{y}}, \mathrm{Co}$ \\
\hline 1453 & Magneli, $\mathrm{Ti}_{3} \mathrm{O}_{5}$ & $\mathrm{Ti}_{3} \mathrm{O}_{5}, \mathrm{Ti}_{2} \mathrm{O}_{3}, \mathrm{TiC}_{\mathrm{x}} \mathrm{O}_{\mathrm{y}}, \mathrm{Co}$ & - \\
\hline 1473 & $\mathrm{Ti}_{3} \mathrm{O}_{5}, \mathrm{Ti}_{2} \mathrm{O}_{3}, \mathrm{TiC}_{\mathrm{x}} \mathrm{O}_{\mathrm{y}}$ & $\mathrm{Ti}_{3} \mathrm{O}_{5}, \mathrm{Ti}_{2} \mathrm{O}_{3}, \mathrm{TiC}_{\mathrm{x}} \mathrm{O}_{\mathrm{y}}, \mathrm{Co}$ & $\mathrm{Ti}_{3} \mathrm{O}_{5}, \mathrm{Ti}_{2} \mathrm{O}_{3}, \mathrm{TiC}_{\mathrm{x}} \mathrm{O}_{\mathrm{y}}, \mathrm{Co}$ \\
\hline
\end{tabular}

*a- $\mathrm{TiO}_{2}$ : anatase-structured $\mathrm{TiO}_{2}, \mathrm{r}-\mathrm{TiO}_{2}$ : rutile-structured $\mathrm{TiO}_{2}$. 


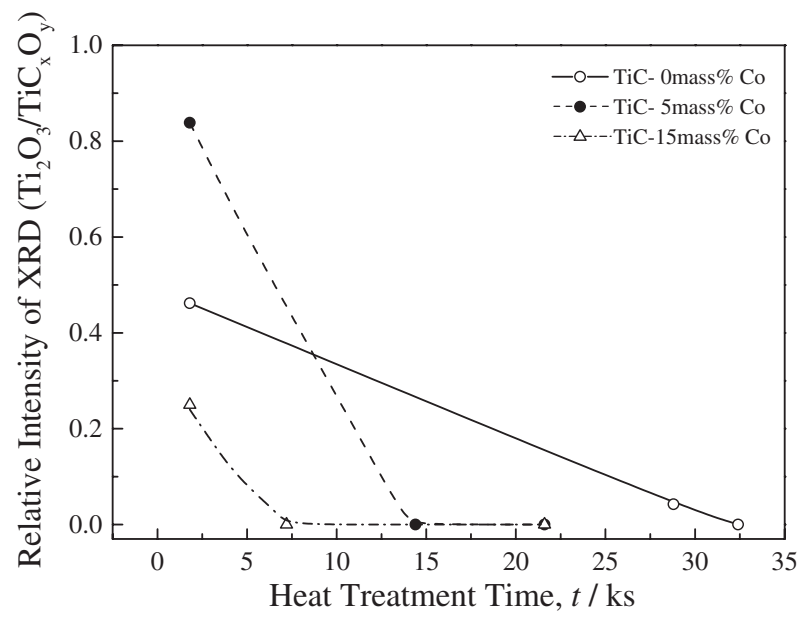

Fig. 4 Change in the relative intensity of the XRD peaks of titanium oxide to $\mathrm{TiC}_{\mathrm{x}} \mathrm{O}_{\mathrm{y}}$ versus heat treatment time at $1473 \mathrm{~K}$.

The reduction temperature of the titanium dioxide and the forming temperature of the titanium oxycarbide decreased with the increasing cobalt content in the titanium-cobaltoxygen-based oxide powder, in spite of the size of the primary particle being larger in the sample with a high cobalt content (Fig. 2). This means that the carbothermal reaction temperatures, the reduction temperature of titanium dioxide and titanium carbide forming temperature, decreased with the increasing amount of $\mathrm{CoTiO}_{3}$ in the starting oxide powder.

Figure 4 shows the change in the relative intensity of the XRD peaks of the titanium oxide to that of $\mathrm{TiC}_{\mathrm{x}} \mathrm{O}_{\mathrm{y}}$ in the samples heated at $1473 \mathrm{~K}$. The peak intensities for the $\mathrm{Ti}_{2} \mathrm{O}_{3}$ and $\mathrm{TiC}_{\mathrm{x}} \mathrm{O}_{\mathrm{y}}$ corresponding to the (116) and (200) reflections, respectively, are used. As shown in Fig. 4, the amount of the retained titanium oxide decreased with the increasing heat treatment time. The heat treatment time needed for complete transformation of the retained titanium oxide to $\mathrm{TiC}_{\mathrm{x}} \mathrm{O}_{\mathrm{y}}$ for the final $\mathrm{TiC}, \mathrm{TiC}-5$ mass $\% \mathrm{Co}$ and $\mathrm{TiC}-15$ mass $\% \mathrm{Co}$ compositions were at least $32.4 \mathrm{ks}, 14.4 \mathrm{ks}$ and $7.2 \mathrm{ks}$, respectively. This means that the titanium carbide formability of the titanium-cobalt-oxygen-based oxide powder by solid carbon increased with the increasing fraction of the cobalt component in the starting oxide powder.

Figure 5 shows the change in the lattice parameter of the $\mathrm{TiC}_{\mathrm{x}} \mathrm{O}_{\mathrm{y}}$ in the samples heated at $1473 \mathrm{~K}$ as a function of the heat treatment time. The lattice parameters were evaluated from the peak positions with the strongest diffractions at about $41.8^{\circ}$. The lattice parameters increased with the increasing heat treatment time. The lattice parameters of $\mathrm{TiC}$ and $\mathrm{TiO}$ are $0.4328-0.4331 \mathrm{~nm}$ and $0.418 \mathrm{~nm}$, respectively. ${ }^{22)}$ Those of solid solution, $\mathrm{TiC}_{\mathrm{x}} \mathrm{O}_{\mathrm{y}}$, are between those of $\mathrm{TiC}$ and $\mathrm{TiO}$. Note that oxygen and nitrogen are common impurities in $\mathrm{TiC}$ and are known to lower the lattice parameters of TiC. Therefore, Figure 5 implies that $\mathrm{TiC}_{\mathrm{x}} \mathrm{O}_{\mathrm{y}}$ formed at the shorter heat treatment time was deoxidized toward $\mathrm{TiC}$ at the longer heat treatment time. Also, the lattice parameter of $\mathrm{TiC}_{\mathrm{x}} \mathrm{O}_{\mathrm{y}}$ approached faster to that of pure $\mathrm{TiC}$ with the increasing cobalt content in the sample. This means that the $\mathrm{TiC}$ formability from $\mathrm{TiC}_{\mathrm{x}} \mathrm{O}_{\mathrm{y}}$ of the titanium-cobaltoxygen-based oxide powder by solid carbon increased with the increasing cobalt content in the starting oxide powder.

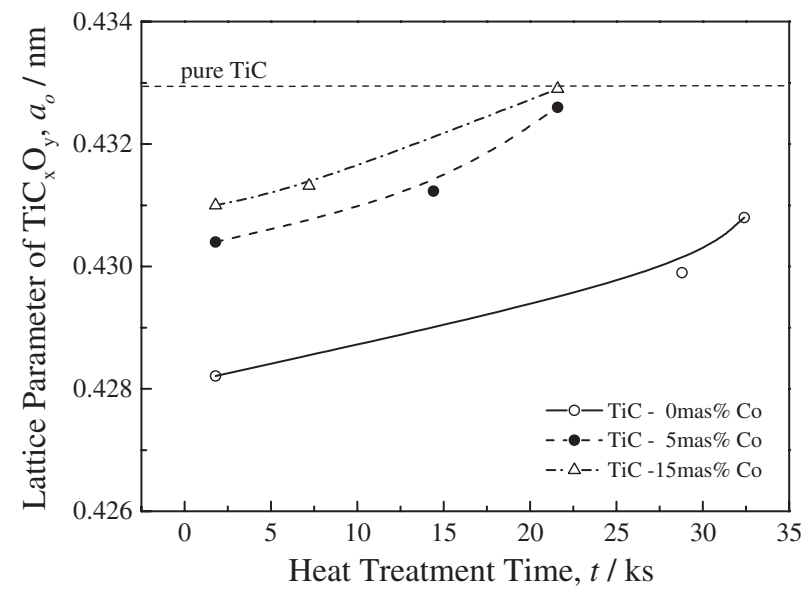

Fig. 5 Change in the lattice parameter of $\mathrm{TiC}_{\mathrm{x}} \mathrm{O}_{\mathrm{y}}$ versus heat treatment time at $1473 \mathrm{~K}$

It is known that the carbothermal reduction of the titanium dioxide was affected by the process parameters of heat treatment, and the particle size and phase structure of the starting oxide. ${ }^{15-17)}$ However, the effects of cobalt on the carbothermal reduction of titanium dioxide have rarely been studied. Earlier work ${ }^{23}$ ) studied the catalytic effect of the cobalt on the formation of tungsten carbide. The addition of the cobalt to the tungsten increased the tungsten carbide formability due to forming a complex carbide with tungsten. This complex carbide increased the tungsten saturation with carbon. In the case of the titanium dioxide with the addition of cobalt, however, no complex carbide with titanium could be found in the X-ray diffraction patterns of the heat-treated samples.

The effects of cobalt on the carbothermal reduction of the titanium-cobalt-oxygen-based oxide powder can be considered from the point-of-view of atomic diffusion. The complex oxide, $\mathrm{CoTiO}_{3}$, was formed by the chemical reaction with titanium dioxide, cobalt oxide and oxygen during the desalting step. Therefore, it was considered that this complex oxide was chemically bonded with titanium dioxide. The $\mathrm{CoTiO}_{3}$ phase was preferentially reduced at a lower temperature than the titanium dioxide. It is postulated that the reduction of the $\mathrm{CoTiO}_{3}$ causes cracking of the titanium dioxide lattice due to the density difference between the titanium dioxide, cobalt and $\mathrm{CoTiO}_{3}$. This crack promotes the mutual diffusion of atoms (or migration of atoms) between the reactants. The lattice cracking during the carbothermal reduction due to the density difference between the reactants and products was experimentally observed by Davidson et $a .^{23)}$ in the case of the tungsten carbide formation. They also proposed that this crack acts on the increasing reaction rate.

Another effect of cobalt on the carbothermal reduction of the titanium-cobalt-oxygen-based oxide powder was a change in the atmosphere in the furnace due to the reduction of $\mathrm{CoTiO}_{3}$. It is postulated that the atmosphere in the heat treatment furnace changed from an inert gas atmosphere of pure argon to the reducing gas atmosphere including $\mathrm{CO}$ gas due to the preferential reduction of $\mathrm{CoTiO}_{3}$. The reducing ability by $\mathrm{CO}$ gas is normally higher than that of solid carbon. 
The relative amount of this gas in the atmosphere will increase with the increasing cobalt content in the starting oxide powder. Therefore, the sample with a high cobalt content has a high titanium carbide formability compared to the one of a low cobalt content, as shown in Figs. 4 and 5. For experimental verification of the cobalt effect, however, fundamental research is needed concerning the reaction analysis based on the thermodynamics, microstructure and gas analysis in the future.

\section{Conclusions}

The present study focused on the analysis of the carbothermic reduction of the titanium-cobalt-oxygen-based oxide powder for understanding the carbothermal reduction step of the spray thermal conversion process for the synthesis of the titanium carbide/cobalt composite powder. The titaniumcobalt-oxygen-based oxide powder can be synthesized by the combination of spray drying and desalting processes using a titanium dioxide powder and cobalt nitrate. The synthesized oxide powders have a mixed phase structure of anatase- $\mathrm{TiO}_{2}$ and $\mathrm{CoTiO}_{3}$ phases when $\mathrm{Co}$ was added. These composite oxide powders are carbothermally reduced to the titanium carbide/cobalt composite powder through four steps with increasing temperature; i.e., reduction of $\mathrm{CoTiO}_{3}$, reduction of anatase- $\mathrm{TiO}_{2}$, formation of titanium oxycarbide and formation of titanium carbide. The reduction temperature of the titanium dioxide and the forming temperature of the titanium carbide decreased with the increasing cobalt content in the starting oxide powder. It was concluded that the complex oxide powder in the synthesized oxide powder, $\mathrm{CoTiO}_{3}$, plays a role in improving the titanium carbide formability during the carbothermal reduction.

\section{Acknowledgements}

This research was supported by a grant from the Center for Advanced Materials Processing of the 21st Century Frontier R\&D Program funded by the Ministry of Commerce, Industry and Energy, Republic of Korea.

\section{REFERENCES}

1) K. J. A. Brookes: Word Directory and Handbook of Hardmetals and Hard Materials, 6th ed., (International Carbide Data, Marsh Barton, 1996) pp. 9-20.

2) K. J. A. Brookes: Word Directory and Handbook of Hardmetals and Hard Materials, 6th ed., (International Carbide Data, Marsh Barton, 1996) pp. 95-102.

3) G. G. Lee, G. H. Ha and B. K. Kim: Powder Metallurgy 43 (2000) 7982.

4) G. G. Lee and W. Y. Kim: Metals and Materials International 11 (2005) $177-181$.

5) K. E. Gonsalves, S. P. Rangarajan and J. Wang: Handbook of Nanostructured Materials and Nanotechnology, ed. by H. S. Nalwa, (Academic Press, London, 2000) pp. 1-56.

6) B. K. Kim, G. H. Ha, D. W. Lee and G. G. Lee: Advanced Performance Materials 5 (1998) 341-352.

7) ASM International Handbook Committee: ASM Handbook, Vol. 7, Powder Metal Technologies and Applications edited by ASM International Handbook Committee, (ASM International, Materials Park, 1998) pp. 932-940.

8) M. Sherif El-Eskandarany: J. Alloys Compound 305 (2000) 225-238.

9) H. Presis, L. M. Berger and D. Schultze: J. European Ceramic Society 19 (1999) 195-206.

10) K. Thorne, S. Ting and C. J. Chu: J. Mater. Sci. 27 (1992) 4406-4414.

11) S. Dunmead, W. Moore and A. Weimer: US Patent No. 53380688, (1993).

12) I. N. Mihailescu, M. 1. De Giorge, C. H. Boulmer-Le Borgne and S. Urdea: J. Appl. Phys. 75 (1994) 5286-5294.

13) S. D. Dunmead, Z. A. Munir and J. B. Holt: J. Mater. Sci. 26 (1991) 2410-2416.

14) G. G. Lee, C. M. Moon and B. K. Kim: J. Korean Powder Metallurgy Institute 10 (2003) 228-234.

15) L. M. Berger: J. Hard Mater. 3 (1992) 3-10.

16) L. M. Berger: J. Mater. Sci. Lett. 20 (2001) 1845-1848.

17) G. G. Lee and B. K. Kim: Mater. Trans. 44 (2003) 2145-2150.

18) S. Morooka, A. Kobat and K. Kusakabe: Ceramic Transaction Vol. 22, Ceramic Powder Science IV, ed. by S. I. Hirano, G. L. Messing and H. Hausner, (The American Ceramic Society, Inc., Ohio, 1991) pp. 109-114.

19) R. Koc: J. Mater. Sci. 33 (1998) 1049-1055.

20) R. Shaviv: Mater. Sci. Eng. A209 (1996) 345-352.

21) L. M. Berger, W. Gruner, E. Langholf and S. Stolle: Int. J. Refract. Met. Hard Mater. 17 (1999) 235-243.

22) R. Koc and J. S. Folmer: J. Mater. Sci. 32 (1997) 3101-3111.

23) C. F. Davidson, G. B. Alexander and M. E. Wadsworth: Metall. Trans. 10A (1979) 1059-1069. 